\title{
Correction to: A combination of omega-3 and plant sterols regulate glucose and lipid metabolism in individuals with impaired glucose regulation: a randomized and controlled clinical trial
}

\author{
Ji-fang Wang ${ }^{1+}$, Hai-ming Zhang ${ }^{2 \dagger}$, Yan-yan $\mathrm{Li}^{1}$, Song Xia ${ }^{3}$, Yin Wei ${ }^{1}$, Ling Yang ${ }^{1}$, Dong Wang ${ }^{1}$, Jing-jing Ye \\ Hao-xiang Li', Jing Yuan ${ }^{1}$ and Rui-rong Pan ${ }^{3 *}$
}

\section{Correction to: Lipids in Health and Disease (2019) 18:106 https://doi.org/10.1186/s12944-019-1048-x}

Following publication of the original article [1], the Authors' Contributions statement need to be changed. It should read as "JFW and RRP conceived of the study and drafted the manuscript. HMZ conceived of the study and revised the manuscript. YYL, SX and GYY participated in the design of the study and performed the statistical analysis. YW, LY, DW, JJY, HXL and JY participated in data curation and helped to draft the manuscript. All authors read and approved the final manuscript.".

\section{Author details}

'Division of Endocrinology, Affiliated Hospital of Jiangsu University, Zhenjiang 212000, Jiangsu, China. ${ }^{2}$ Department of General Surgery, Affiliated Hospital of Jiangsu University, Zhenjiang 212000, Jiangsu, China. ${ }^{3}$ Department of Clinical Nutrition, Affiliated Hospital of Jiangsu University, No. 438 Jiefang Road, Zhenjiang District 212000, Jiangsu, China.
Published online: 16 March 2020

\section{Reference}

1. Wang J, Zhang H, Li Y, et al. A combination of omega-3 and plant sterols regulate glucose and lipid metabolism in individuals with impaired glucose regulation: a randomized and controlled clinical trial. Lipids Health Dis. 2019;18:106. https://doi.org/10.1186/s12944-019-1048-x.

*Correspondence: panrr_med@126.com

${ }^{\dagger} \mathrm{J}$ i-fang Wang and Hai-ming Zhang contributed equally to this work.

${ }^{3}$ Department of Clinical Nutrition, Affiliated Hospital of Jiangsu University, No. 438 Jiefang Road, Zhenjiang District 212000, Jiangsu, China

Full list of author information is available at the end of the article

(c) The Author(s). 2020 Open Access This article is licensed under a Creative Commons Attribution 4.0 International License, which permits use, sharing, adaptation, distribution and reproduction in any medium or format, as long as you give appropriate credit to the original author(s) and the source, provide a link to the Creative Commons licence, and indicate if changes were made. The images or other third party material in this article are included in the article's Creative Commons licence, unless indicated otherwise in a credit line to the material. If material is not included in the article's Creative Commons licence and your intended use is not permitted by statutory regulation or exceeds the permitted use, you will need to obtain permission directly from the copyright holder. To view a copy of this licence, visit http://creativecommons.org/licenses/by/4.0/ The Creative Commons Public Domain Dedication waiver (http://creativecommons.org/publicdomain/zero/1.0/) applies to the data made available in this article, unless otherwise stated in a credit line to the data. 